\title{
Evaluation of adhesion in polymeric fibre reinforced cementitious composites
}

\author{
H.R. Pakravan ${ }^{\text {a }}$, M. Jamshidi ${ }^{\text {b,*, }}$ M. Latifi ${ }^{\text {a }}$, F. Pacheco-Torgal ${ }^{c}$ \\ a Department of Textile Engineering, Textile Excellence E Research Centers, Amirkabir University of Technology, Iran \\ ${ }^{\mathrm{b}}$ Department of Chemical Engineering, Polymer group, Iran University of Science and Technology, Iran \\ c C-TAC Research Unit, University of Minho, 4800 Guimarães, Portugal
}

\section{A R T I C L E I N F O}

Article history:

Accepted 30 August 2011

\section{Keywords:}

Adhesion

Loss function

Polymeric fibres

Cement matrix

\begin{abstract}
A B S T R A C T
In this study adhesion of some polymeric fibres to a cement matrix was evaluated both by a theoretical and by an experimental approach. In common methods adhesion of the fibres to the cementitious materials is determined by pull-out test. This test evaluates the energy failure during the fibre drawing out. This paper analyzes the adhesion theory for fibre reinforced cementitious composites to separate the share of the chemical and mechanical adhesion expressing new parameters, which are effective in the adhesion behaviour. Explanations about how the different fibres, matrix properties, test factors and environmental conditions can affect the adhesion results are given. It was found that for fibre/cement composites the fracture energy due to the interfacial interactions is for several orders of magnitude smaller that the polymeric fibre losses function. By employing adhesion theory, fibre/cement interactions are better described by a simple relationship of their surface free energy. Determination of the loss function (energy dissipation) leads us to predict the fibre behaviour in the cement matrix and the selection of the appropriate reinforcement.
\end{abstract}

(c) 2011 Elsevier Ltd. All rights reserved.

\section{Introduction}

Application of short, randomly and distributed fibres for reinforcement of cementitious materials has been studied intensively in last decades. Wide varieties of fibres are used for this application including organic fibres, natural cellulose and inorganic fibres [1]. It is found that the reinforcement with fibres has been proved to be an effective and economical way to convert brittle cementitious materials to a tough and ductile product [2]. A critical parameter, which has a major effect on the mechanical performance of fibre reinforced cementitious composites, is the adhesion between the fibres and the cementitious matrix. A traditional method to evaluate the adhesion is using pull-out tests. Fibre pull-out behaviour contributes to the energy absorption ability of the fibre reinforced cement matrix. Fibre/cement matrix adhesion allows the stress transfer between the fibres and the cement matrix $[3,4]$. The performance of fibre reinforced composites is also strongly dependent on the debonding behaviour of the fibres. For this purpose, the relationship between the required load for debonding and the displacement of a fibre when it pulls out from the cement matrix serves as an important parameter in the design of cementitious composite materials $[5,6]$. Increasing the interface strength between the fibres and

\footnotetext{
* Corresponding author. Tel.: +98 2177240541 .

E-mail address: mjamshidi@iust.ac.ir (M. Jamshidi).
}

the matrix leads to the improvement of composite properties. Regarding to its important role in cementitious composite materials, fibre/cement matrix interface has been studied extensively $[7,8]$. Many of these investigations study fibre/cement adhesion energy and the methods of its determination. Based on these studies two methods for measuring fibres adhesion to a cement matrix has been suggested; a direct and an indirect one [9]. In the direct method like the pull-out test, fibres movement in a matrix gives the interface strength of the fibre/cement matrix. In the indirect method, the result of some mechanical tests such as flexural and tensile tests is used to predict bonding properties. Conventionally what is often measured in pull-out test is the practical work of adhesion $(G)$, which is a macroscopic measure of the fibres debonding from a rigid interface (fibre/cement interface) as fracture toughness. This measurement has been performed by some researchers [10-12]. Many pull-out test methods differ in the pulling-out process, sample production mold and methodology are introduced $[13,14]$. Although, bonding of fibres to the cementitious matrix have been studied by many researchers, it seems that none of them considered all aspects in the adhesion mechanism such as the fibres wetting properties and the role of fibre/cement interfacial (chemical) interactions, mechanical/ interlocking bonding and effect of fibres physical/mechanical properties on the adhesion energy. Both surface polarity and surface roughness contribute to the fibre wettability within the cement matrix. Understanding the forces that develop at the interface of fibre/cement matrix is helpful in the selection of the right fibres and 
the proper surface treatment of fibres. The present study describes the adhesion of three types of polymeric fibres into a cement matrix. The fibres physical/mechanical properties and the surface properties (wettability, surface free energy, etc) were investigated. Also, a hardened cement paste was evaluated in terms of its surface free energy in water to cement ratio of 0.5 . Afterwards, fibre/cement pull-out specimens were prepared and tested. The specimens were used to determine the pull-out curve (pull-out load versus displacement). By employing the adhesion theory the thermodynamic work of adhesion and the loss function was calculated. Finally, the proportion of each type of adhesion mechanism, e.g. mechanical bonding and chemical bonding in fibre/cement matrix were quantified.

\section{Adhesion theory}

Controlling of wettability and interfacial adhesion are preliminary important step in determining the interfacial properties of fibre reinforced composites. Good interfacial adhesion between fibre and matrix helps in efficient stress transfer across the interface. In the following, theory of contact angle, wettability, and adhesion is discussed. On the basis of the adhesion theory the adhesion between two substances can be attributed to, mechanical interlocking, electrostatic, diffusion and adsorption/surface reaction [15]. In general we can divide the adhesion mechanism into two main groups, including [16-19]:

A. Mechanical bonding; i.e. mechanical interlocking;

B. Chemical and physical bonding; electrostatic, diffusion, adsorption/surface reaction, weak boundary layers.

The wettability, chemical bonding and weak boundary layer have been postulated to describe the mechanism of adhesion in status of adsorption/surface reaction. According to the Fowkes [20] description there is a needed energy for separation of liquids from bulks where molecules in the intimate contact area have an intermolecular force. This energy induced from the intermolecular attractions, which arise from a variety of well-known intermolecular forces including van der Waals forces, covalent bonding forces, hydrogen bonding forces, etc. This used energy is called surface free energy. London dispersion forces are the major intermolecular forces, which exist in all types of materials and always produce an attractive force.

Gent and Schultz [21] proposed that there is a relation between interfacial adhesion energy and adherence energy (practical work of adhesion), which is composed of two terms: the thermodynamic work of adhesion and a dissipation function, which also depends on the adhesion energy $W[22,23]$

$G=W+\Phi$

$\Phi=W f\left(a_{T} V\right)$

in which $G$ is work of the adhesion energy (which is measured by usual adhesion test methods such as peel and pull-out test), $W$ is the thermodynamic work of adhesion (energy required for breaking of the interfacial chemical interactions), $\Phi$ is the dissipation function relating to the time/temperature translation factor $\left(a_{T}\right)$ and separation speed $(V)$.

This idea was extended by other authors and the equation is written in the general from [24-28], as follows:

$G=W\left(1+\left\{1+\Pi\left(\sigma_{y s}\right)\right\}\{1+\Phi(T)\}\{1+\Psi(v)\}\right)$

where $\sigma_{y s}$ is the yield strength of the softer material, $T$ is the temperature and $v$ is the separation rate. In addition, $\Pi$ describes the amount of plasticity produced around the crack tip during propagation along the interface, $\Phi$ corresponds to visco-elastic dissipation in the crack tip region and $\Psi$ accounts for all other energy consumption outside the interfacial region [27]. In the present study Eq. (1) is simplified to form Eq. (2) as following:

$G=W(1+\varphi)$

where $\varphi$ is a loss function, which depends on total energy dissipated viscoelastically or plastically during fracture. The thermodynamic work of adhesion $(W)$ is a reversible energy, which is needed to break apart the two adhered materials [29]. Therefore, it represents bonding energy of interfacial chemical interactions. In the present study, these two types of adhesion were investigated. The Fowks's methodologies and adhesion theory were employed to study the fibre/cement matrix adhesion for all fibres. The work of energy $(G)$ at the interface of the fibres and the cement paste was evaluated using a pull-out test. The work of the thermodynamic adhesion is expressed as following (Dupré's equation):

$W=\gamma_{1}+\gamma_{1}-\gamma_{12}$

where $\gamma_{1}$ and $\gamma_{1}$ are the surface energies of phase 1 and 2, and $\gamma_{12}$ is the interfacial free energy of the phase adhered to each other. In Eq. (1), $G$ is the energy per unit area of the fracture material.

The interfacial energy $\left(\gamma_{12}\right)$ can be determined using the geometric means equation of the Owens \& Wendt as following [30]:

$\gamma_{12}=2\left(\gamma_{1}^{d} \gamma_{2}^{d}\right)^{0.5}+2\left(\gamma_{1}^{p} \gamma_{2}^{p}\right)^{0.5}$

The results of work of thermodynamic adhesion $(W)$ and dissipation function $(1+\varphi)$ for each fibre type and cement matrix have been calculated in this study.

\section{Materials and methods}

\subsection{Materials}

The cement used in this study was ordinary Portland cement type I. The synthetic fibres used in this work were nylon66, polypropylene and acrylic fibres. To evaluate fibres mechanical properties a single fibre tensile test is performed under standard atmosphere on a Fafegraph HR (Moünchengladbach, Germany) tensile tester machine with a constant rate of crosshead speed of $20 \mathrm{~mm} / \mathrm{min}$ accordance to the requirements of ISO 527. The physical/mechanical properties of fibres are given in Table 1. Fig. 1 shows the physical properties of the fibres cross section.

\subsection{Methods}

\subsubsection{Pull-out test specimen preparation}

Specimens for pull-out test were prepared with a specific mold that has been designed and made for this research. The schematic of the designed mold for specimen preparation was shown in Fig. 2. After adjusting the required embedded length of monofilament by movement of Lower Part 2 with respect to Lower Part 2, monofilament fibres were aligned across of mold, as shown in Fig. 2. When fibres end fixed on the double side adhesive, which adhere on the base plate, Upper Parts 1 and 2 were fixed by screws to Lower Parts

Table 1

Properties of fibres

\begin{tabular}{llllc}
\hline Fibre type & $\begin{array}{l}\text { Diameter } \\
(\mu \mathrm{m})\end{array}$ & $\begin{array}{l}\text { Density } \\
\left(\mathrm{gram} / \mathrm{cm}^{3}\right)\end{array}$ & $\begin{array}{l}\text { Tensile strength } \\
(\mathrm{MPa})\end{array}$ & $\begin{array}{l}\text { Elongation } \\
(\%)\end{array}$ \\
\hline Polypropylene & 25 & 0.91 & 326 & 180 \\
Nylon66 & 26 & 1.14 & 1122 & 32 \\
Acrylic & 40 & 1.19 & 344 & 48 \\
\hline
\end{tabular}


a

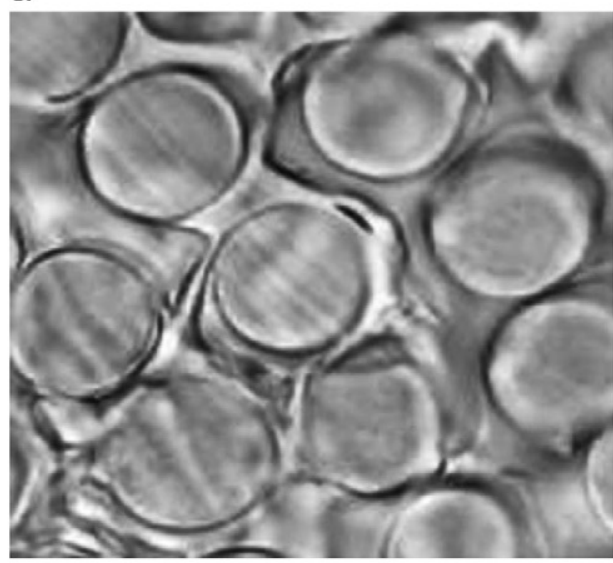

b

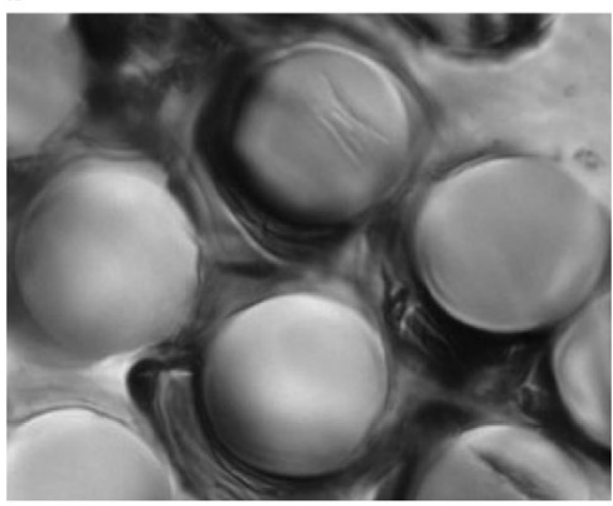

C

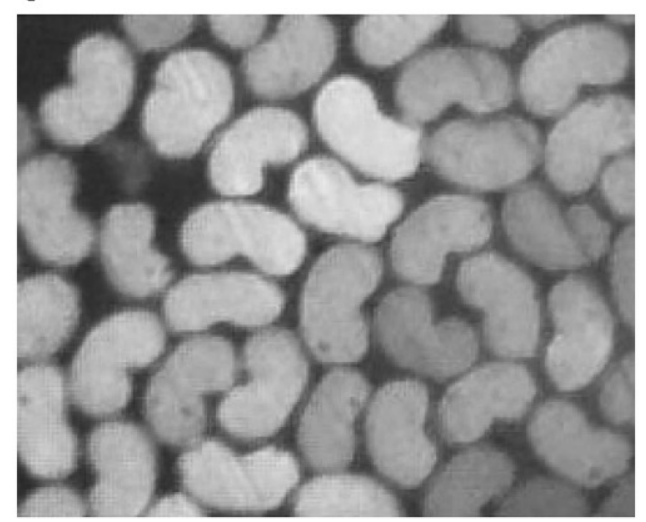

Fig. 1. Cross-sectional shape of fibres, (a) nylon66, (b) polypropylene and (c) acrylic.

1 and 2, respectively. The operation should be done in absence of any stretch in monofilaments. Finally, after assembling of Upper parts on the Lower parts, cement paste was introduced to vacant space in mold.

The specimens also prepared with a matrix made of 0.5 , water to cement ratio. After demolding, specimens were subjected to a conditioning cure room in an environment of $23 \pm 2{ }^{\circ} \mathrm{C}$ and $95 \pm 5 \%$ of relative humidity for 28 days. Pull-out tests were carried out for specimens with an embedded length of $10 \mathrm{~mm}$.

\subsubsection{Pull-out test method}

For investigation of bonding characteristics of single fibres, pull-out tests was performed. The pullout tests were carried out in an Instron testing machine at a crosshead rate of $0.02 \mathrm{~mm} / \mathrm{s}$. Fig. 3 shows schematic description of the test set-up. The free length of a single fibre was $10 \mathrm{~mm}$. Load-displacement curves at pull-out process were recorded.

\subsubsection{Surface free energy}

3.2.3.1. Hardened cement paste. The surface free energy of the cement paste at a water to cement ratio of 0.5 was measured using a tensiometer testing machine. The average surface free energy was obtained from measurements on 5 drops of each liquid. The probe liquids used were water and Diiodomethane. The water surface free energy was measured at $20^{\circ} \mathrm{C}$ and was found to be $\gamma_{l}=72.1 \mathrm{~mJ} / \mathrm{m}^{2}$. The Diiodomethane had a surface free energy of $50.80 \mathrm{~mJ} / \mathrm{m}^{2}$. Polar and disperse components of used liquids surface tensions for measuring cement surface free energy are given in Table 2 .

3.2.3.2. Fibres. The surface free energy analysis of the fibres was measured by the Wilhelmy plate technique. This is one of the most important for the determination of wetting parameters. The principal is based on the use of a single fibre immersed in a test liquid according to Fig. 4 Surface free energy analysis of fibre is determined by measuring the contact angle of a variety of liquids, which having known their polar and dispersion components of total surface free energy. The used liquid were water and Diiodomethane and their polar and disperse components are presented in Table 2. The measurements were made using Krüss K14 tensiometer at a controlled temperature of $22 \pm 1{ }^{\circ} \mathrm{C}$. The average surface free energy of fibres was obtained from 5 measurements for each fibre.

\section{Results and discussion}

\subsection{Pull-out results}

The pull-out behaviour of all fibres is illustrated by the loadextension curves in Fig. 5. The average results were obtained on the basis of three specimens for each fibre. The result shows that acrylic fibre has better pull-out behaviour in comparison to polypropylene and nylon66 fibres. The nylon66 fibre illustrated approximately similar behaviour in pull-out result to the polypropylene fibres. The cross section of acrylic fibres is not round, as shown in Fig. 1c. Due to this fact, the mechanical bonding could be increased by a frictional effect between the fibre and the cement matrix. In other words, acrylic fibres have a much higher contact surface to the cement matrix, and it led to increasing frictional resistance during pull-out between fibre and matrix.

The average maximum pull-out strength of fibres from cement matrix was shown in Fig. 6. The acrylic fibre was shown approximately two times higher bonding strength compared with other fibres.

In the pull-out load versus slip curve three major regions can be determined as shown schematically in Fig. 7. Initially, zone 1 corresponds to the debonding process along the fibre-matrix interface. Since the fibre fully debonds $\left(P_{\max }\right)$, the load drops quickly $\left(P_{f r}\right)$ and the resistance to pull-out is mainly provided by friction between the fibre and the matrix at region 3.

According to the pull-out test results, the value of $G$, which is the energy per unit area of the fracture material calculated from debonding region as following:

$G=\int_{0}^{L_{d}} F d l / 2 \pi d \times L$

in which $F, L_{d}, d$ and $L$ are the pull-out load of fibres, the length of the debonded zone, fibre diameter and fibres length embedded in cement matrix, respectively. The values of work of adhesion were calculated for all fibres and shown in Table 3. 


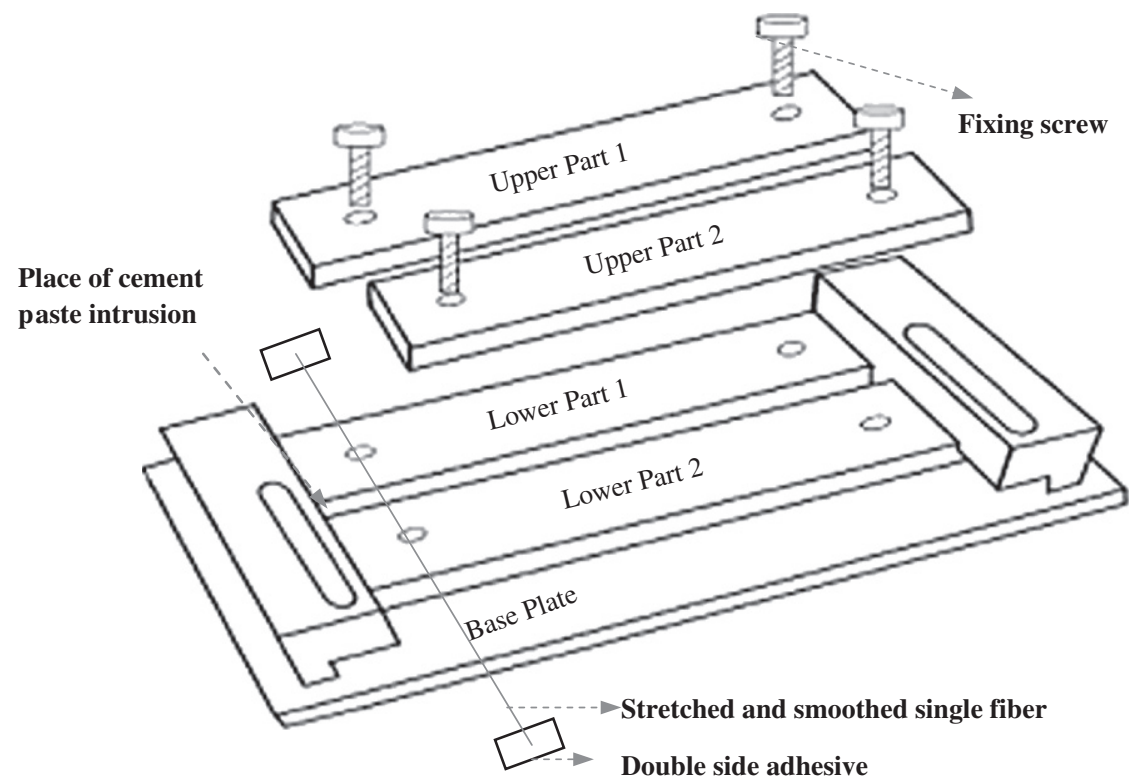

Fig. 2. Schematic image of specimen preparation mold.

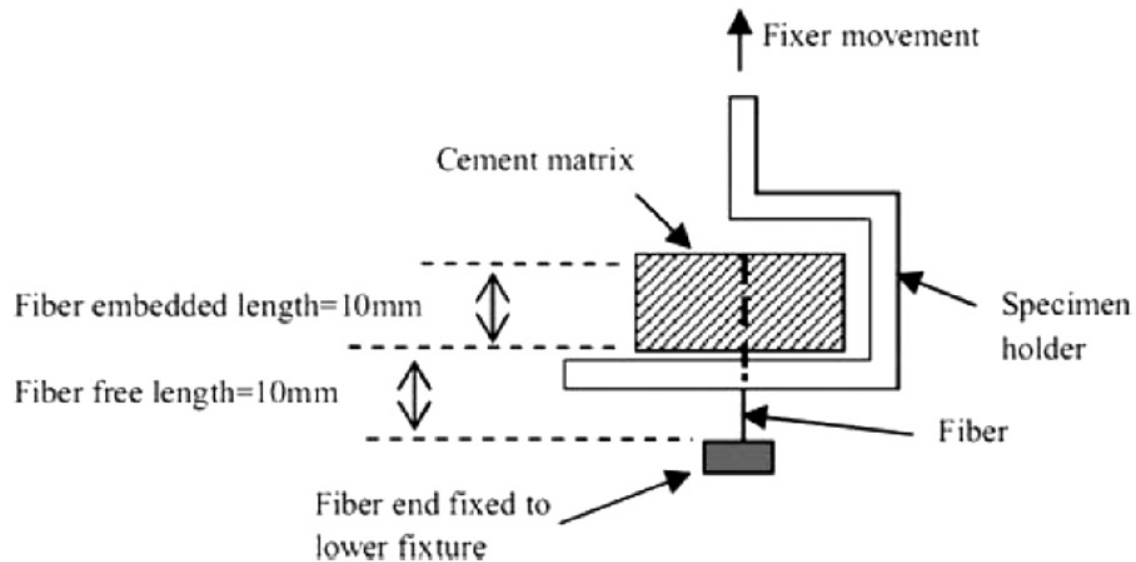

Fig. 3. Schematic of the single fibre pull-out test set-up [31].

Table 2

Surface free energy $\left(\mathrm{mJ} / \mathrm{m}^{2}\right)$ and its components of liquids used.

\begin{tabular}{llcc}
\hline Liquid & $\gamma_{l}^{d}$ & $\gamma_{1}^{p}$ & $\gamma_{l}$ \\
\hline Water $\left(\mathrm{mJ} / \mathrm{m}^{2}\right)$ & 21.80 & 51 & 72.80 \\
Diiodomethane $\left(\mathrm{mJ} / \mathrm{m}^{2}\right)$ & 48.5 & 2.3 & 50.80
\end{tabular}

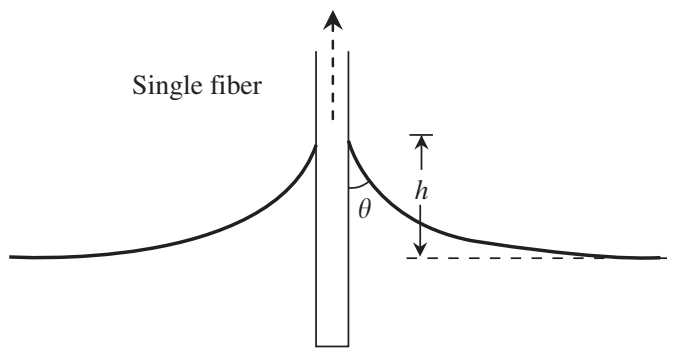

Fig. 4. Schematic description of Wilhelmy technique contact angle measurement.

\subsection{Surface free energy analysis}

Cement matrix surface free energy was evaluated by applying Young's true contact angle, $\theta$, values of water and Diiodomethane

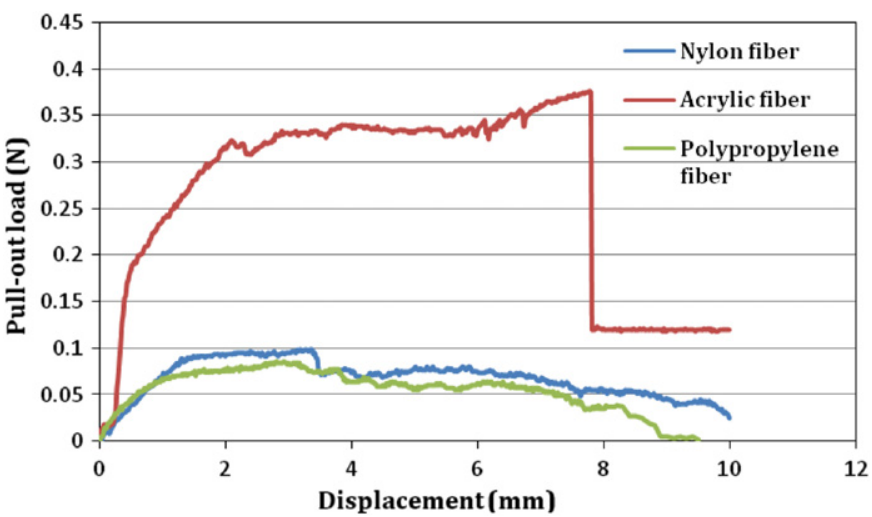

Fig. 5. Pull-out curves of fibres from cement matrix at 28 days cement curing.

into the Owens \& Wendt method Eq. (6) as following [30]:

$\gamma_{l}(\cos \theta+1)=2\left(\gamma_{s}^{d} \gamma_{l}^{d}\right)^{0.5}+2\left(\gamma_{s}^{p} \gamma_{l}^{p}\right)^{0.5}$

where $\theta$ is the contact angle (Fig. 8), $\gamma_{l}$ the surface free energy of the liquid, $\gamma_{s}$ the surface free energy of the solid; superscripts $d$ and $p$ corresponded to the dispersive and polar components of the surface free energy of the liquid, $l$, and the solid, $s$, respectively. 


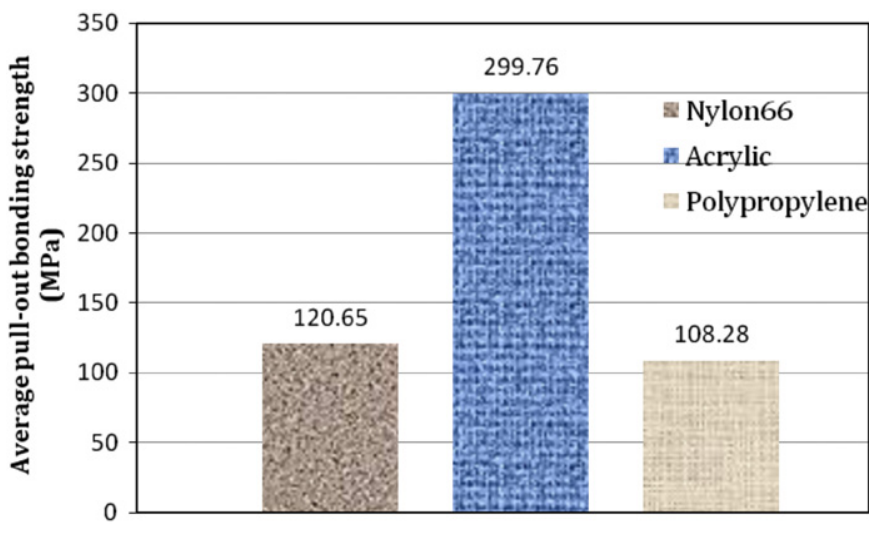

Fig. 6. Average maximum pull-out bonding strength in fibre/cement interface.

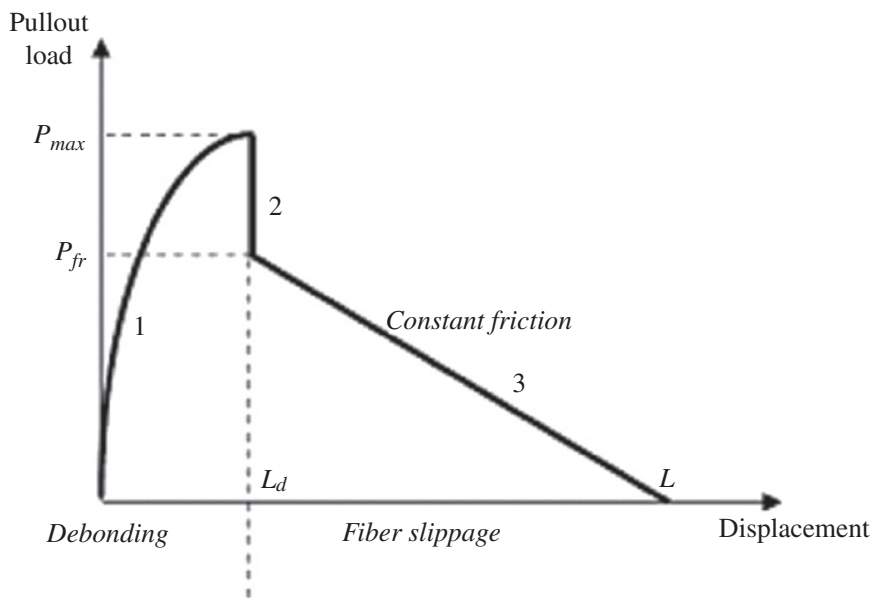

Fig. 7. Schematic description of fibre pull-out curve [2].

Table 3

Work of adhesion $G$, in pull-out process.

\begin{tabular}{lll}
\hline Fibre type & $\begin{array}{l}G\left(\mathrm{~mJ} / \mathrm{m}^{2}\right) \\
\left(\times 10^{3}\right)\end{array}$ & $\begin{array}{l}\text { Standard } \\
\text { deviation }\left(\times 10^{3}\right)\end{array}$ \\
\hline Acrylic fibre & 187 & 7.02 \\
Polypropylene fibre & 124 & 6.03 \\
Nylon66 fibre & 137 & 6.51 \\
\hline
\end{tabular}

The cement matrix surface free energy obtained using two equations for the liquids used. The total value of $\gamma_{s}$ is derived from the sum of the dispersive and polar components.

The total surface free energy of cement specimen is given in Table 4.

The contact angle measured by Wilhelmy technique is in relation to the force required $F$, to immerse or remove a single fibre from a liquid of known surface tension at constant velocity according to:

$F=\gamma_{l} \pi d \cos \theta$

where $d$ is the single fibre diameter, $\gamma_{l}$ is the surface tension of the used liquids and $\theta$ is the contact angle between the single fibre and liquid. The polar and dispersive components of the fibre surface free energy $\gamma_{s}^{p}$ and $\gamma_{s}^{p}$ are determined based on Eq. (6). The results of the surface free energy of all fibres are given in Table 5.

According to the results the acrylic fibre has the higher surface free energy and the polypropylene fibre showed the lower surface free energy. On the basis of the above results and Eqs. (1)-(3), the

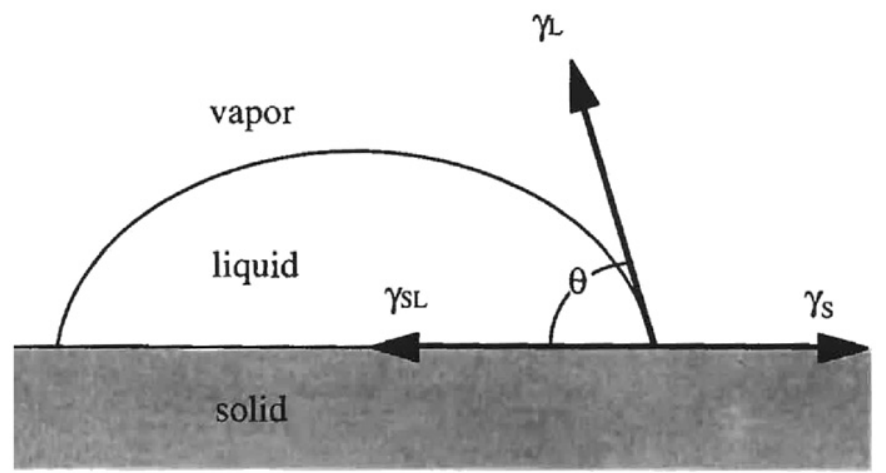

Fig. 8. Description of contact angle as a measure of wettability. Adopted from Ref. [24].

Table 4

Surface energy $\left(\mathrm{mJ} / \mathrm{m}^{2}\right)$ of hardened cement paste with $w / c$ ratio of 0.5 .

\begin{tabular}{lllll}
\hline Material & $\begin{array}{l}\text { Surface free energy } \\
\left(\gamma_{s}\right)\left(\mathrm{mJ} / \mathrm{m}^{2}\right)\end{array}$ & $\begin{array}{l}\text { Standard } \\
\text { deviation }\end{array}$ & $\begin{array}{l}\text { Disperse part } \\
\left(\gamma_{s}^{p}\right)\left(\mathrm{mJ} / \mathrm{m}^{2}\right)\end{array}$ & $\begin{array}{l}\text { Polar part } \\
\left(\gamma_{s}^{p}\right)\left(\mathrm{mJ} / \mathrm{m}^{2}\right)\end{array}$ \\
\hline $\begin{array}{l}\text { Cement } \\
\text { matrix }\end{array}$ & 50.06 & 4.01 & 28.88 & 21.18 \\
\hline
\end{tabular}

Table 5

Surface energy $\left(\mathrm{mJ} / \mathrm{m}^{2}\right)$ of fibres.

\begin{tabular}{lllll}
\hline Fibre types & $\gamma_{s}\left(\mathrm{~mJ} / \mathrm{m}^{2}\right)$ & $\begin{array}{l}\text { Standard } \\
\text { deviation }\end{array}$ & $\gamma_{s}^{d}\left(\mathrm{~mJ} / \mathrm{m}^{2}\right)$ & $\gamma_{s}^{p}\left(\mathrm{~mJ} / \mathrm{m}^{2}\right)$ \\
\hline Acrylic & 67.3 & 2.05 & 63 & 4.3 \\
Polypropylene & 43.5 & 3.54 & 39.6 & 3.9 \\
Nylon66 & 62.3 & 1.56 & 59.9 & 2.4 \\
\hline
\end{tabular}

Table 6

Work of thermodynamic adhesion $(W)$ and loss function $(\varphi)$.

\begin{tabular}{lllll}
\hline Solid-solid system & $\begin{array}{l}W \\
\left(\mathrm{~mJ} / \mathrm{m}^{2}\right)\end{array}$ & $\begin{array}{l}\text { Standard } \\
\text { deviation }\end{array}$ & $(1+\varphi)$ & $\begin{array}{c}\text { Standard } \\
\text { deviation }\end{array}$ \\
\hline $\begin{array}{l}\text { Acrylic fibre-cement } \\
\text { matrix }\end{array}$ & 104.39 & 3.15 & 1790 & 75.59 \\
$\begin{array}{l}\text { Polypropylene } \\
\text { fibre-cement matrix }\end{array}$ & 85.81 & 3.74 & 1450 & 50.08 \\
$\begin{array}{l}\text { Nylon66 fibre-cement } \\
\text { matrix }\end{array}$ & 97.44 & 2.55 & 1400 & 57.83 \\
& & & & \\
\hline
\end{tabular}

thermodynamic work of adhesion and loss function were calculated. Results are shown in Table 6.

It was found that acrylic fibres had a higher chemical bonding to the cement matrix in comparison to other fibres. The thermodynamic work of adhesion of the polypropylene fibres was lower than the other fibres. The lower ' $W$ ' means a lower chemical interaction, which is normal in the case of the polypropylene/ cement system. The thermodynamic work of adhesion $(w)$ demonstrates wet ability of fibres by cement paste. Good wetting of the fibres by the matrix during mixing is a prerequisite to proper consolidation of composite materials.

The value of $(1+\varphi)$ indicated that, bonding strength of fibres to the cement matrix is directly related with the energy dissipation. The value of ' $W$ ' is of several orders of magnitudes smaller than the loss function $(1+\varphi)$, which shows the importance of energy losses by means of plastic and viscoelastic dissipation to chemical bonding in fibres-cement systems. For all series, the properties of cement matrix are similar. Therefore, the difference between fibre/cement pull-out behaviours should be attributed to the different energy absorption capability and the different properties 
of the fibres (such as the modulus of elasticity and the viscoelastic properties). In the polypropylene/cement system, the fibres extended due to the stress generated during the mechanical load. The elongation of the fibres cause the damping of stress thus the fibre cement interface to pull-out the fibre decreases. This phenomenon causes high energy dissipation on bonding of polypropylene fibres to the cement matrix. According to its surface free energy, polypropylene fibre has a low tendency to be wetted by the cement paste. Thus in the interface between the fibre and the matrix, a gap filled by water is created [10]. The hollow space is a sustainable situation for growing large size $\mathrm{CH}$ crystals. These large size crystals cause high friction energy and high adhesion energy. Also, polypropylene fibres have lower superficial resistance, therefore the contact with the cement particles during the pulling-out from cement matrix causes changes in fibre shape and as a result more stress would be damped. The fibre surface deformation in contact with hydrated cement crystals is described by a SEM micrograph in Fig. 9. Consequently because of these two factors stated above, the amount of force needed to the pull-out test would be approximately similar to the nylon66 fibres. It is known that the nylon66 fibre has high tensile strength and high molecular weight; thereby elongation of these fibres is low. The results of the work of thermodynamic adhesion show that the nylon66 have a chemical adhesion to the cement paste. So when the composite system is exposed to the stress, the force is transferred directly to the interface, then causing pull-out of fibre from the matrix.

The acrylic fibre with non-circular cross section (bean shape), has many mechanical interlocking in the interface with the cement matrix. These fibres also have relatively large percentage

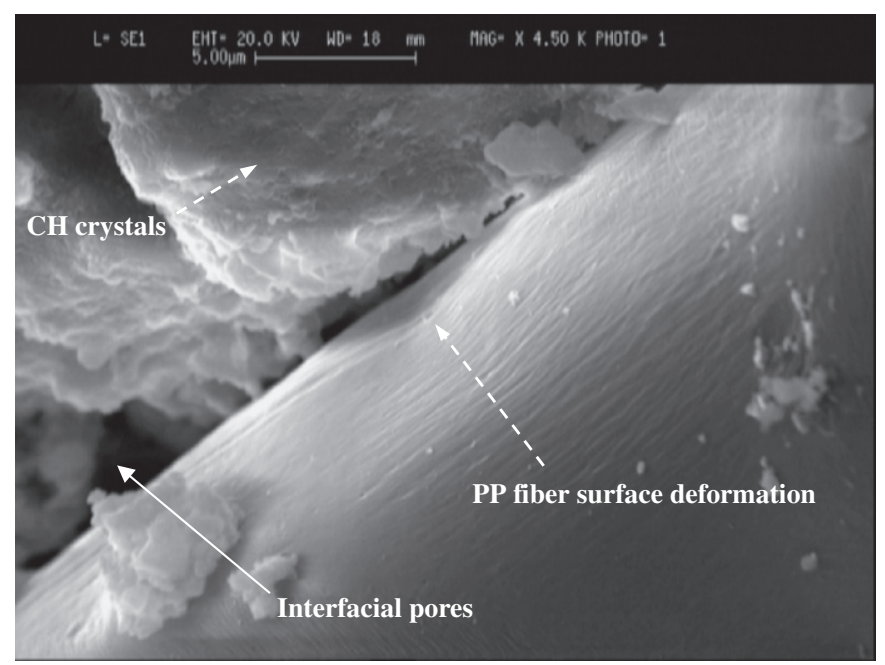

Fig. 9. SEM micrograph of polypropylene fibre at fracture zone of cement composite. of elongation than nylon fibres. When stress enters into the acrylic fibres some of it is spent into the fibre elongation and the rest is spent to deal with the mechanical contact at the interface. Since the share of mechanical energy dissipation due to sliding friction is more than the chemical adhesion, the conflict in the interface will cause the fibre rupture. Previous investigations conducted on polymer-polymer; show that the loss function is dependent on the temperature, contact angle and velocity of the test [32-36]. According to the results mentioned before it is proposed that during the pull-out of fibres from surrounded matrix, loss function of the fibres depend on the modulus of elasticity, the fibre shape and the fibre's elongation. However, it is reasonable to assume that the parameters like the angle of tensile force and the temperature influence the rate of energy loss. On the basis of the loss function results special attention should be given to the improvement of plastic-elastic dissipation (by means of mechanical contact) in spite of only the chemical bonding between them. Thereafter mechanical bonding in fibre/cement interface has an important role to enhance the mechanical performance of cement composites materials.

\subsection{Microscopic analysis}

Examination of acrylic fibres pulled-out from the matrix by SEM microscopy demonstrated that a layer of cement particles are attached to the surface of these fibres, as shown in Fig. 10. The longitudinal images of this fibres point that there is an affinity between the cement bulk and the acrylic fibres. These fibres have a hydrophilic nature, which is similar to the hydrophilic nature of the cement paste, due to the affinity of these materials to each

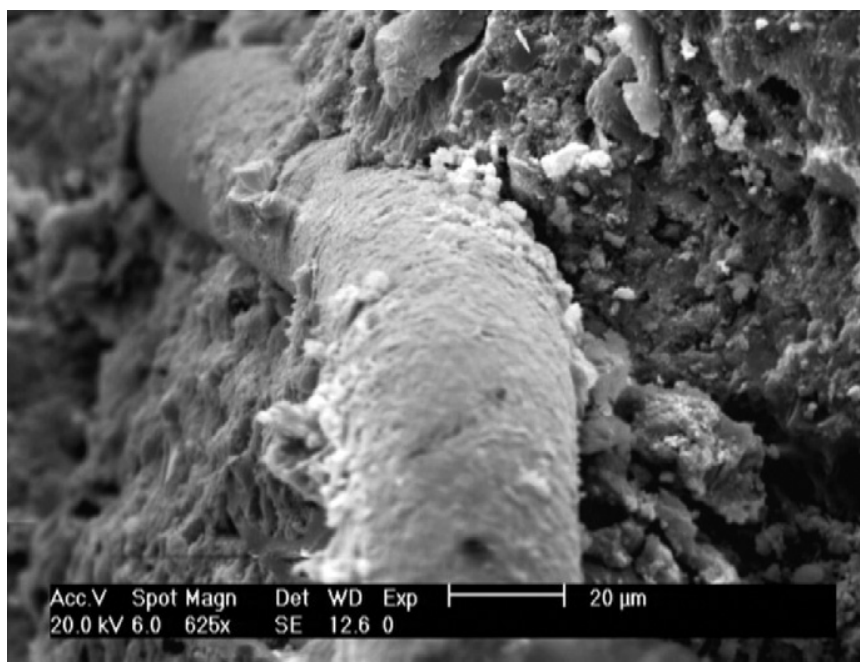

Fig. 11. A acrylic fibre surrounded by cement matrix [37].

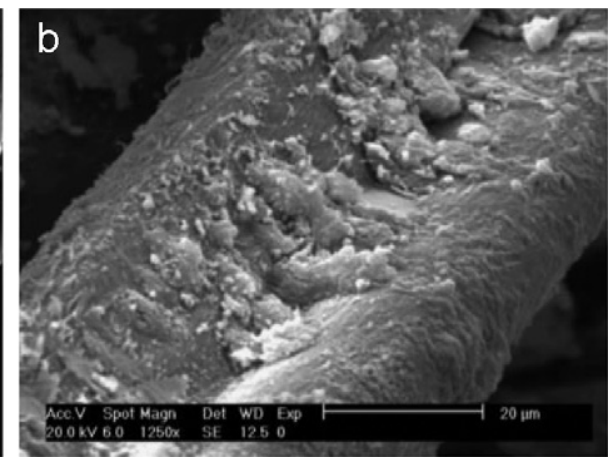

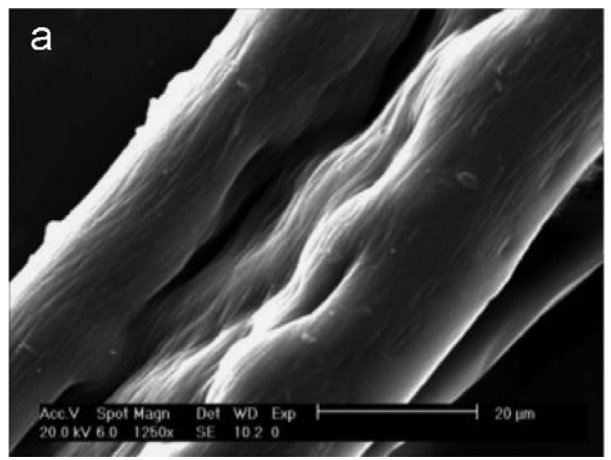

Fig. 10. SEM micrographs of acrylic fibres, (a) before pull-out test, (b) pulled-out from cement matrix [31]. 

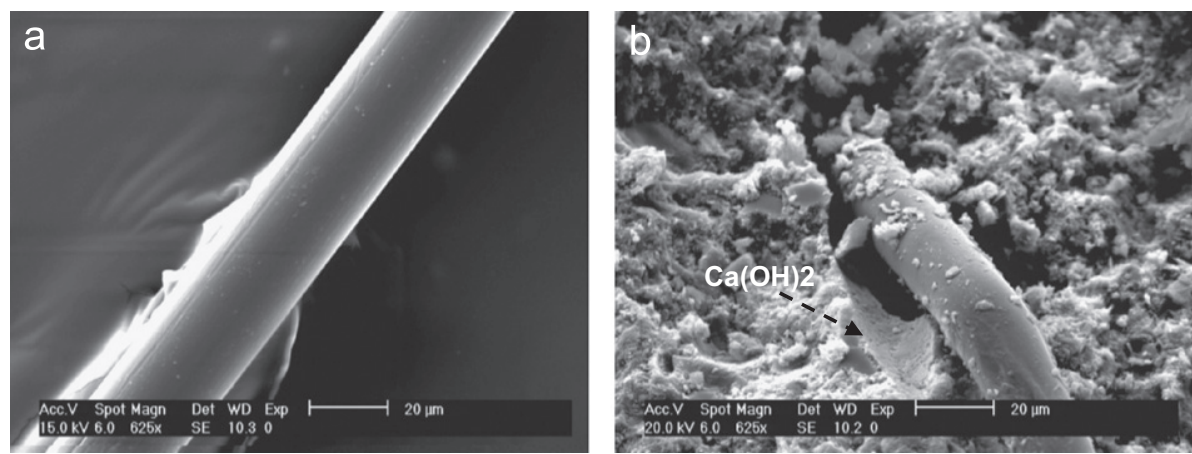

Fig. 12. SEM micrographs of polypropylene fibres, (a) before embedding in cement matrix, (b) after composite fracture.
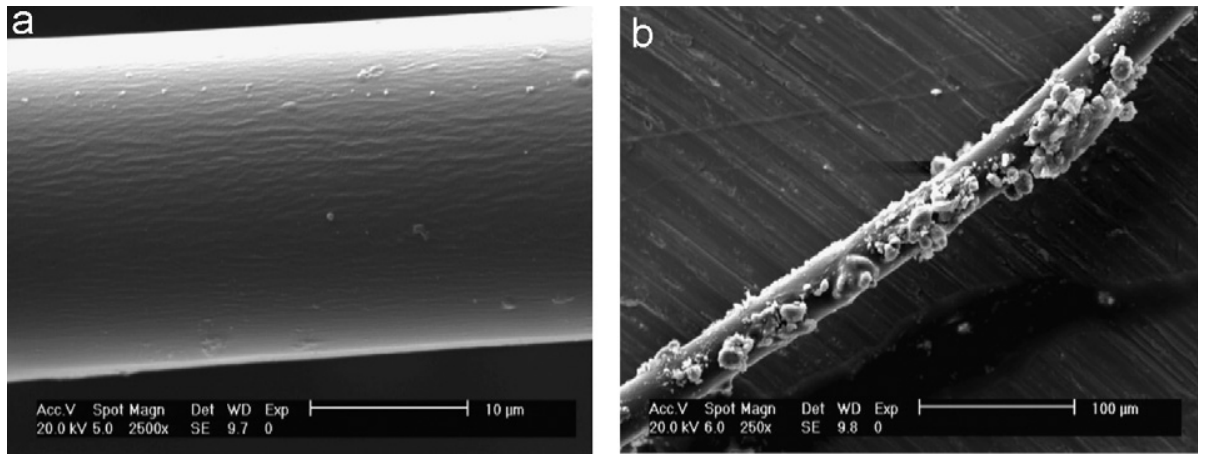

Fig. 13. SEM micrographs of nylon66 fibres, (a) before pull-out test, (b) pulled-out from cement matrix.

other; therefore a chemical adhesion may be occurred. It was clearly shown that in Fig. 11, acrylic fibre is surrounded entirely by compact cement matrix. This revealed that better wettability by cement paste was take place for acrylic fibre. However, a modest increase in $W$ (perfect wettability) may result in a large increase in adhesion energy where it was shown in Fig. 10 for acrylic fibres.

SEM micrographs of the polypropylene fibre at the fracture zone of the composite revealed that the fibre surface unlike shown in Fig. 12(a) has an embossed roughness at the longitudinal direction, (Fig. 12(b)). This shall be attributed to the presence of large crystals at the interface. Due to non-polar nature of the polypropylene fibres, which surface free energy of polypropylene fibre in lower than cement paste, thus, a gap is generated between the fibre and the cement matrix. In this vacant space water could be located around the fibres. Thereafter, during the hydration process large $\mathrm{Ca}(\mathrm{OH})_{2}$ crystals are grown at fibre/cement transition zone [10]. As shown in Fig. 13 the evaluation of the nylon66 pulled-out fibres reveal that some cement particles attach to the fibres surface. Based on this observation, it can be said that nylon66 fibres had a chemical bonding to the cement matrix.

\section{Conclusion}

The results obtained in the present work showed that the energy loss (plastic and elastic dissipation) plays a relevant role on the maximum load obtained in the pull-out test of the fibres from the cement matrix. In the past, it was believed that the chemical interactions between the cement hydration products and the fibres had a crucial influence in the fibre-cement bonding strength, but the results of the present work show they play just a minor role. In this investigation the theory of adhesion, was applied to the fibre-cement system. The loss function $(1+\varphi)$ or energy dissipation capacity of the system under load was calculated for all fibre-cement systems. It was concluded that the fibres bonding to the cement matrix is affected by visco-elastic or plastic energy dissipation due to the mechanical contacts at the interface, the modulus of elasticity and the elongation of the fibres around the crack tip and in the bulk of the materials during pull-out test.

\section{References}

[1] Kim Dj, Naaman A, El-Tawil ES. Cem Concr Compos 2008;30(10):917.

[2] Wang Y. Mechanics of fiber reinforced cementitious composites. PhD thesis, Massachusetts Institute of Technology; 1989.

[3] Bentur A. J Mater Civ Eng 2000;12(1):217.

[4] Yan L, Jenkins CH, Pendleton RL. Cem Concr Res 2000;30(3):403.

[5] Li VC, Chan YW, Wu HC. In: Proceedings of the international symposium on brittle matrix composites, Warsaw, 1994, pp. 7-16.

[6] Bentur A, Mindess S. Fiber Reinforced Cementitious Composites. UK: Elsevier Science Publishing Ltd; 2007.

[7] Bentur A. J Mater Civ Eng 2000;12(1):21725.

[8] Chan Y-W, Li VC. J Mater Sci 1997;32:5287.

[9] Reinhardt HW, Naaman AE. High performance fiber reinforced cement composites. In: RILEM Proceedings 15; 1992

[10] Peled A, Zaguri E, Marom G. Compos: Part A 2008;39:930.

[11] Najm H, Naaman AF, Chu T-J, Robertson RE. Adv Cem Based Mater 1994; $1: 115$.

[12] Singh S, Shukla A, Brown R. Cem Concr Res 2004;34:1919.

[13] Katz A, Li VC. J Mater Sci Lett 1996;15:1821.

[14] Chan YW. Fiber/cement bonding property modification in relation to interfacial microstructure, PhD thesis. Michigan; 1994.

[15] Ebnesajjad S. Adhesives Technology Handbook. 2nd edition. Norwich, NY: William Andrew Inc.; 2009.

[16] Ryutoku Y. Adhesion and Bonding in Composites. New York: Marcell Dekker; 1990.

[17] Jamshidi M, Afshar-Taromi F, Mohammadi N. Iran Polym J 2005;14(3):229.

[18] Zhandarov S, Mäder E. Compos Sci Technol 2005;65(1):149.

[19] Gorbatkina YA, Ivanova-Mumjieva VG. Int J Adhes Adhes 1997;17(4):329.

[20] Fowkes FM. J Adhes Sci Technol 1990;4:669.

[21] Gent AN, Schultz J. J Adhes 1972;3:281.

[22] Guillemenet J, Bistac S, Schultz J. Int J Adhes Adhes 2002;22:1

[23] Chaudhury MK, Owen. MJ. Langmuir 1993;9(1):29.

[24] Andrews EH. J Mater Sci 1974;6:887. 
[25] Gent AN, Lai S-M. J Polym Sci Part B: Polym Phys 1994;32:1543.

[26] Johnson KL. Tribol Int 1998;31(8):413.

[27] Garif YS, Energy dissipation in polymer-polymer adhesion contacts. PhD thesis: University of Minnesota; 2003.

[28] Crosby AJ, Shull KR. J Polym Sci Part B: Polym Phys 1999;37(24):3455.

[29] Kim JK, Mai YW. Engineered Interfaces in Fiber Reinforced Composites. Elsevier; 1998.

[30] Owens D, Wendt R. J Appl Polym Sci 1969;13:1741.

[31] Pakravan HR, Jamshidi M, Latifi M. J Appl Polym Sci 2010;116:1247.
[32] Schultz J, Nardin M. In: Mittal KL, Pizzi A, editors. Adhesion Promotion Techniques. Marcel Dekker; 2002. p. 1-26.

[33] Gent AN, Kinloch AJ. J Polym Sci Part A: Polym Chem 1971;9:659.

[34] Andrews EH, Kinloch AJ. Proc R Soc London A 1973;332:401.

35] Packham DE. In: Pizzi A, Mittal KL, editors. Handbook of Adhesive Technology. 2nd edition. Marcel Dekker ed.; 2003.

[36] Jamshidi M, Afshar-Taromi F. J Adhes Sci Technol 2007;3:169.

[37] Pakravan HR, Jamshidi M, Latifi M. Investigation on polymeric fibers as reinforcement in cementitious composites: flexural performance. J Ind Text 2011; first published on September 26. doi:10.1177/1528083711421358. 